\title{
Open, connective, flexible and innovative research is the way to fight new global challenges; A lesson learned from our first year of the COVID-19 pandemic
}

\author{
Elizabeth Pavez Loriè* \\ Leibniz Research Institute for Environmental Medicine, Düsseldorf, Germany
}

While we are fast approaching the end of the first month of 2021, we can look back and ponder on the old year and the long tail it has and will have on this present year and our future. The beginning of this new decade challenged the scientific community in several ways; the spread of a new virus that became a global health crisis to which the scientific community responded by doing what was necessary to not only identify, but also find ways to eliminate this new threat. Also, we have been forced to identify the weak links in our scientific work, which not only consists of research, but of teaching and explaining science to others.

As we waited for the vaccine to be developed (more vaccine candidates are on their way) and now for its distribution we have been submitted to many different forms of restrictions. Research institutions have not been excluded from this, in fact many institutions have needed to restrict the access to bench work research, which in turn has seen many groups opting to stop their laboratory work altogether. Many were and are still concerned about how to maintain animals, cell lines and cultures during lockdown [1]. It has been reported that between one month to six months of work might have been lost due to lab shutdowns with large differences seen between wet lab (73\%) and dry lab (31\%) [1].

Even though groups have been able to focus on tasks that could be done remotely, the work that should have been conducted by students, PostDocs and young group leaders with short deadlines or grant limitations, are facing a new reality. This also includes these groups' participation in scientific events such as national and international conferences, workshops and practical courses which are significant grounds for the dissemination of research findings, to learn new skills, meet future supervisors and networking for future collaborations. Fortunately, we have already seen leading research funders such as the European Horizon 2020 research program, US National Institutes of Health, UK Royal Society and also national and local funders offering support by introducing a series of measures to provide "administrative relief" such as extensions to the duration of funding, relocation of research funds to meet the costs of working remotely [2].

Within the group of scientists that have suffered the adversity of the pandemic the most are those with children, particularly women, as in most countries they are still the main family caretaker [3]. Proofs can be found in the submission and pre-prints, where it has been seen that women in science have been submitting fewer manuscripts than their male counterparts in comparison to pre-pandemic times [4]. Obviously, the output of publishing is only one measure of productivity in research and it will therefore be interesting to see if similarities can also be observed in grant submissions, awards, promotions, teaching, networking etc. [5]. It is therefore important that measures are taken to provide relief for researchers with children, where not only care taking alternatives (such as day care) should be further developed, but a discussion and decision concerning the flexibility of deadlines and monetary support is very important.

SARS-Cov-2 and COVID-19 has not only led to negative disturbances in the research world, as many researchers began working for the first time on issues related to COVID redirecting their research agendas in a crisis and many research institutions and nations celebrated this response [1]. The New York Times noted "Never before, researchers say, have so many countries focused simultaneously on a single topic with such urgency" [6]. This movement has allowed researchers to identify and share information like never before. Even though brainstorming over videoconferences, sharing data, ideas and findings has been part of scientific research for a long time it has been restricted by a community spirit that has been known for being secretive about their data. In many ways COVID-19 has been a wakeup call for diminishing these constrictions and open scientific knowledge more. This also includes efforts seen to support colleagues to collect the data they need to keep their labs operational during this pandemic [1]. Let's hope that this newfound sense of purpose will prevail and that it will be the new norm in our field of work.

As part of the publish or perish mentality we live by as researchers and the interconnections and dependence in publishing, this pandemic has provided the opportunities of free speedy open early-stage research sharing with datasets like; the COVID-19 Open research Dataset (CORD-19) or the European COVID-19 Data Platform [7]. Also, preprints have enabled large-scale-early-stage research communication, and sites like medRxiv or bioRxiv, publish new material daily. But it has also enabled the politicization of clinical care findings in an environment of enormous public interest, where these services have had to develop review systems to prevent some of the misuse of data $[8,9]$.

Other scientific communication has been even less formal than preprints. At early stage in the pandemic some research teams were using

*Correspondence to: Elizabeth Pavez Loriè, Leibniz Institute for Environmental Medicine, Düsseldorf, Germany, E-mail: Elizabeth.Pavezlorie@IUFDuesseldorf.de

Received: January 29, 2021; Accepted: February 08, 2021; Published: February 11,2021 

pandemic

tools such as Slack for rapid conversations. And networks including Mendeley and ResearchGate, facilitated sharing and collaboration for COVID-19 researchers. We have also seen the benefits of social media where more open debates and discussions by scientists with the public have occurred [1]. Let us hope that this newfound cause of the scientific community to be part of the discussion in society, owning the role as public informers, doesn't fade away but is kept and/or intensified.

The surge in published articles in relation to COVID-19 cannot go unnoticed and tools such as literature hubs have become great tools to keep up with the published SARS CoV-2/COVID-19 articles [7]. Some journals also launched a fast-track peer-review process that clearly demonstrates the possible efficiencies that could be implemented, at least under emergency conditions, into their editorial processes.

As we all know open access (OA) publications, serves the public good and now many articles related to SARS-Cov2 and COVID-19 are available free of charge even from journals that are normally not OA journals in response to the "Free read" petition to unlock coronavirus related research for the world's scientists. With this movement we have been able to experience what it would be like to live in a world based on free-for-all medical information [7] and of course the question arises, how this movement can influence and change the publishing mentality in research journals for good. Even if many OA journals today are based on an article processing charges (APCs) system for publication and those fees are covered by the author's institution or by the research funder, it leads to an unequal chance to publish in OA journals for those nations or institutes that do not offer or have that kind of economic support. Nevertheless, it is a common misconception that all OA journals charge APCs for publication. According to the data available in the Directory of Open Access Journals there are about 1800 non-APC OA medical and human biology scientific journals [9]. These "free" journals are funded by governmental institutions, among others. Maybe the key to solving this problem of inequality in publishing can be found by using the newfound tools from publishers to share COVID-19 related articles and include the already existing knowledge by the many non-APC OA journals.

Last but not least on the list of challenges facing the medical community during this pandemic, has been to speed up the development of COVID-19 therapeutics by repurposing pharmacological agents to treat disease symptoms. Timelines for traditional drug development are too long for the urgency demanded by this pandemic, which has led the field of drug discovery to re-imagine repurposing of approved agents. The Accelerating COVID-19 Therapeutics Interventions and Vaccines (ACTIV)-public-private partnership was formed to streamline pathways for drugs to months instead of years, for biological evaluation in standard preclinical assays and models, supporting their consideration for clinical development [10]. As we see new pathogenic threats appear, the field of preclinical assays and in vitro models can become a gold standard, supporting prioritization for clinical trials if given the incentive to develop more effective and in vivo like platforms. All these efforts are a big step forward into making drug discovery and clinical use more flexible and interconnected, giving the community a chance to be more prepared for new pandemics.

Doctors without borders, published an illustration which describes their wishes for 2021. It shows the insight we all have had to embrace. It has 5 wishes: i) Everyone shares fruits of scientific progress, ii) Everyone shares knowledge for common benefit, iii) Everyone is open about the true costs of new medicine, iv) Everyone attaches strings to research funding and $v$ ) everyone works together to solve problems [11]. The scope of OA journals such as this one, which connect the fields of medicine with social and ethical sciences is important to fulfill such a wish list. All in all, the wish to continue working in a more open, connective, flexible and innovative research environment is hopefully here to stay.

\section{References}

1. Radecki J, Schonfeld R (2020) The impacts of COVID-19 on the Research Enterprise Ithaka $\mathrm{S}+\mathrm{R}$.

2. Subramanya SH, Lama B, Acharya KP (2020) Impact of COVID-19 pandemic on the scientific community. Qatar Med J 21. [Crossref]

3. Myers KR, Tham WY, Yin Y, Cohodes N, Thursby JG, et al. (2020) Unequal effects of the COVID-19 pandemic on scientists. Nat Hum Behav 4: 880-883. [Crossref]

4. Ribarovska AK, Hutchinson MR, Pittman QJ, Pariante C, Spencer SJ (2021) Gender inequality in publishing during the COVID-19 pandemic. Brain Behav Immun 91: 1-3. [Crossref]

5. Viglione G (2020) Are women publishing less during the pandemic? Here's what the data say. Nature 581: 365-366. [Crossref]

6. Apuzzo M, Kirkpatrick D (2020) Covid-19 changed how the world does science, together. The New York Times.

7. Skoric L, Glasnovic A, Petrak J (2020) A publishing pandemic during the COVID-19 pandemic: how challenging can it become? Croat Med J 61: 79-81. [Crossref]

8. Kaiser J (2017) The preprint dilemma. Science 357: 1344-1349.

9. DOAJ. Webpage: The Directory of Open Access Journals.

10. Grobler JA, Anderson AS, Fernandes P, Diamond MS, Colvis CM, et al. (2020) Accelerated Preclinical Paths to Support Rapid Development of COVID-19 Therapeutics. Cell Host Microbe 28: 638-645. [Crossref]

11. Peng V (2020) Our wishes for 2021, Doctors without borders.

Copyright: (C2021 Loriè EP. This is an open-access article distributed under the terms of the Creative Commons Attribution License, which permits unrestricted use, distribution, and reproduction in any medium, provided the original author and source are credited. 